\title{
CARTOGRAFIA DE SI: o processo de criação através dos territórios particulares e compartilhados no Instagram
}

\author{
Yorrana P. Maia de Souza \\ UNAMA \\ yosouza@globo.com
}

\begin{abstract}
Resumo: O interesse deste artigo é melhor compreender a multiplicidade que perpassa variáveis de processos de criação em moda na contemporaneidade, por meio da reflexão sobre uma cartografia composta por registros particulares e por registros fotográficos compartilhados no Instagram do criador. O modelo de observação e pesquisa parte do conceito de Rizoma de Gilles Deleuze e Felix Guattari, um mapa aberto, conectável e desmontável. Dentre outros movimentos de entradas e saídas, os diálogos com Suely Rolnik sobre a Cartografia e com Michel Foucault sobre a Escrita de Si fundamentam o entendimento acerca do ato de criar como uma construção de Si.
\end{abstract}

Palavras-chave: Processo de criação; rizoma; cartografia; moda.

\begin{abstract}
The interest of this essay is to better understand the multiplicity of variables that permeates creation processes in the contemporary fashion, through reflection on a map composed of private records and photographic records of the creator shared on Instagram. The observation model and research is based on the concept of Rhizome as presented by Gilles Deleuze and Felix Guattari, an open map, attachable and detachable. Among other movements of inputs and outputs, dialogues with Suely Rolnik on Cartography and Michel Foucault on "self writing" underlie the understanding of the act of creation as a construction of the self.
\end{abstract}

Keywords: creative process; rhizome; cartography; fashion.

\section{INTRODUÇÃO}

Em seu abecedário1, Deleuze (1988-1989) discorre sobre a letra " $z$ ", de ziguezague, que lembra o que dizia sobre universais e singularidades. A questão é: como relacionar as singularidades díspares ou relacionar os potenciais? Em termos físicos, podemos imaginar um caos cheio de potenciais; mas como relacioná-los? Como

\footnotetext{
${ }^{1}$ Realização de Pierre-André Boutang. Entrevista feita por Claire Parnet, foi filmada nos anos 1988-1989. Tradução e legendas: Raccord. Disponível em: http://www.youtube.com/watch?v=FPp8uC2WqYc. Acesso em: 16 de setembro de 2012.
} 
relacionar potenciais de um percurso criador não linear e fragmentado em uma narrativa que assuma esse ir e vir, em movimento ziguezagueante?

Partimos, então, do conceito de Rizoma de Gilles Deleuze e Felix Guattari, um mapa aberto, conectável e desmontável. Dentre outros movimentos de entradas e saídas, os diálogos com Suely Rolnik sobre a Cartografia e com Michel Foucault sobre a Escrita de Si fundamentam o entendimento acerca do ato de criar como uma construção de Si e de suas redes de conexões de referências em fluxo e não lineares. Para isso, fomos recolhendo conceitos e teorias, deslocando-os e adaptando-os ao campo da moda, e assim articulando a investigação e os conceitos que fossem pedindo passagem.

O que nos interessa é entender o percurso, o meio, as construções de $\mathrm{Si}$, o ato de criar, o que gera o movimento da criação e quais fragmentos do seu cotidiano particular e compartilhado estão inseridos nas coleções desse criador. Portanto, buscamos compreender o processo de criação que ressalte a não-linearidade, que force a abandonar certos mapas, para então entender que a criação assume outro ritmo na contemporaneidade: acelerado e atravessado pelas novas tecnologias, de passos rápidos e em constantes mudanças.

\section{IDAS E VINDA: RIZOMA, CARTOGRAFIA E CONEXÕES}

Atualmente estamos vivendo outro regime de tempo e de espaço que produz outras configurações nas subjetividades atravessadas por conexões efêmeras, cambiantes e mutantes. Para Martin Barbero (2004, p. 200) "a aceleração das mudanças faz parte do movimento da comunicação - a instantaneidade da informação possibilita uma nova rentabilidade e uma transformação das relações possíveis, multiplicando-as".

Portanto, parece acertado nos tempos atuais ponderar formas contemporâneas de pensar a criação em processo que partam dessas relações múltiplas, decompondo e compondo territórios. Nesse sentido, o processo de criação:

Nada tem a ver com o cultivo de hábitos criados em cativeiros criativos, ao contrário, é inventar estados de si que desbordam de um destino pessoal. Invenção é intervenção na existência movido por uma profunda necessidade. É construir uma 'câmara de ecos', que ressoe o vivo e você junto. Inventar não é colorir o mundo, mas corar-se de mundos. (PRECIOSA, 2010, p. 75)

Preciosa (2010) pede para inventarmos movido por desejo, e que esta invenção ressoe o vivo e nós juntos, elaborações de $\mathrm{Si}$ e dos projetos em curso. Nesse movimento, encontros inesperados trazem outros desdobramentos e possibilidades. Sendo assim, acompanhar o engendramento do pensamento é mais importante do que pontuar suas representações. "Escrever nada tem a ver com significar, mas com agrimensar, cartografar, mesmo que sejam regiões ainda por vir" (DELEUZE; GUATTARI, 1995, p. 13)

Esses novos encontros e sentidos produzidos passam a fazer parte da reserva deste criador que compõe seu repertório através da pluralidade e da transitoriedade das informações no seu ambiente contemporâneo. Desse modo, há por parte do criador, uma necessidade de guardar alguns elementos, que podem ser possíveis 
concretizações dos seus projetos ou podem ajudar nessa concretização. "Os documentos de processo são, portanto, registros materiais do processo criador. São retratos temporais de uma gênese que agem como índices do percurso criativo." (SALLES, 2004, p. 17)

A própria construção do pensamento criativo já traduz uma prática de $\mathrm{Si}$, pois o criador está o tempo todo refletindo seu ambiente, seus sonhos, objetos, suas lembranças mesmo quando mergulha no caos para dar corpo a outras sensações que pedem passagem. Se a subjetividade é uma construção social, então ela se metamorfoseia o tempo inteiro a partir dos novos agenciamentos com os quais o estilista entra em contato. A criação em processo é, portanto, uma construção de Si.

Michel Foucault se perguntava: por que um pintor trabalharia, se não fosse para ser transformado por sua pintura? E por que alguém escreveria, poderíamos nos perguntar? Para intervir em si mesmo, para se infligir ideias, quase sempre improváveis, para se usar de vários modos, para se contrair e distender, para que os insights insistam e que com eles você possa compor algumas ações perceptíveis. (PRECIOSA, 2010, p. 21)

Em todo o caso, além da pesquisa que é feita para os seus projetos em curso, o criador está sempre refletindo sobre a sua maneira de pensar e fazer. As novas impressões do mundo vão metamorfoseando também sua maneira de olhar para esse mundo, assim novas estratégias de marca surgem e o comportamento das clientes muda, aparecendo novos desejos de criar novas imagens. Na verdade, a inquietude e a busca de novos direcionamentos movem o ato de criar, pois o estilista é afetado pelo seu tempo e para aprender a viver com esse novo tempo ele exercita essa elaboração de Si. Mas como compreender a multiplicidade e não linearidade em que o processo de criação se dá? Em que sentido esses encontros e conexões formam projetos de design de moda?

Os filósofos Deleuze e Guattari (1995, p. 8) argumentam que "as multiplicidades ultrapassam a distinção entre a consciência e o inconsciente, entre a natureza e a história, o corpo e a alma. As multiplicidades são a própria realidade, e não supõem nenhuma unidade, não entram em nenhuma totalidade".

Para esses autores, o modelo de realização das multiplicidades é o rizoma, e os vetores que as atravessam são os territórios e graus de des-re-territorialização. Assim, os territórios mudam necessariamente à medida que aumentam as conexões que se estabelecem. Não devemos buscar a unidade e sim as variedades de medidas, novas misturas que se definem pelas desterritorializações que mudam de natureza ao se conectarem a outras.

Em primeiro lugar, é necessário entender o território não como um lugar estático com uma delimitação espacial e sim flexível e itinerante, pois, de acordo com Deleuze e Guattari (1997), o próprio agenciamento territorial se abre para outros tipos de agenciamentos que o arrastam. Nesse sentido, a desterritorialização é o movimento pelo qual se abandona o território, é a operação de linha de fuga.

A desterritorialização, por sua vez, é inseparável de reterritorializações. É que a desterritorialização nunca é simples, mas sempre múltipla e composta: não apenas porque participa a um só tempo de formas diversas, mas porque faz convergirem velocidades $\mathrm{e}$ movimentos distintos (...). A reterritorialização como operação 
original não exprime um retorno ao território, mas essas relações diferenciais interiores à própria desterritorialização, essa multiplicidade interior a linha de fuga. (DELEUZE; GUATTARI, 1997, p. 225)

Construir o pensamento criador é desterritorializar-se. Isto quer dizer que o pensamento só é possível na criação e, para que algo seja criado, é necessário romper com o território existente, criando outros. Novos agenciamentos são necessários. No entanto, a desterritorialização do pensamento é sempre acompanhada da reterritorialização, que é a coleção criada, é o novo conceito.

No campo da moda, esses movimentos tomam proporções ainda maiores se levarmos em conta que a efemeridade e a busca pelo novo são o cerne do seu funcionamento, portanto estamos sempre nos des-re-territorializando. Preciosa (2009), ao refletir sobre a moda contemporânea, comenta como a nossa cultura parece moverse aglutinando informações, funcionando à base de sucessivas colagens, assimilando, devorando e intervindo no repertório selecionado, com vistas a produzir outros arranjos sígnicos. Afinal, vestimos formas que nos projetem num espaço físico e afetivo, num espaço simbólico de trocas culturais: espaço de invenção e reinvenção subjetivas.

O estilista, portanto, vai recolhendo, juntando tudo o que the parece necessário, e esses encontros e trocas com o território local, global e virtual, com o seu tempo e consigo mesmo geram sentidos possíveis em suas coleções. Para Le Breton (2003), a cultura virtual, longe de ser uma ilusão, é uma outra dimensão do real, na qual o imaginário estabelecido na relação com a tela alimenta a relação com o mundo: não é um devaneio desligado da densidade das coisas. Esta perspectiva é importante para entender o funcionamento da moda contemporânea, o criador e seu modo de pesquisa e registro inseridos também no contexto virtual.

A construção de sentidos ao longo do processo de criação em moda é imbricada desses devires, deslocamentos, emoções e inquietações que geram o movimento da criação; e da necessidade de dizer algo através de discursos vestíveis, surgem coleções que serão usadas por corpos que circulam pelos espaços, ressignificando estas roupas.

Salles (2004) diz que o criador está em estado de alerta, com a sensibilidade suspensa, à espera e à procura de sensações e, na medida em que ativam sensivelmente o artista, são criadoras. O processo criativo é essa rede de relações entre mundos e a subjetividade do criador. Um processo contínuo.

Desenvolver uma coleção em moda é antes de tudo essa manifestação do desejo de se expressar através de roupas que se inicia ao fazer inferências e leituras de mundo e descobrir novas possibilidades. Uma continuidade que não é fruto de uma única boa ideia, mas de um processo em construção, o qual, segundo Salles (2004), está localizado em um espaço e em um tempo que inevitavelmente afetam o estilista.

Ao pesquisar o processo de criação, a partir dos registros que o criador guarda em seus acervos, particular e compartilhado no Instagram $^{2}$, movemo-nos entre hibridizações e fluxos de pistas que estão em movimentos constantes e, portanto,

\footnotetext{
${ }^{2}$ Segundo Manovich (2005), as mídias sociais ocupam-se de objetos e paradigmas culturais capacitados por todas as formas de computação, inclusive as tecnologias de comunicação em rede. O Instagram é um tipo de mídia social. É um aplicativo móvel gratuito que permite aos usuários tirar uma foto, aplicar um filtro e depois compartilhá-la em uma variedade de redes sociais, incluindo o próprio Instagram. Projetado inicialmente para o uso em dispositivos móveis Apple iOS, que opera em telefones móveis Iphone, posteriormente também foi desenvolvido para os aparelhos com a tecnologia Android. A empresa for criada em 2010, por Kevin Systrom e o brasileiro Mike Krieger.
} 
exigem do pesquisador outro tipo de mapeamento, que se pauta mais na construção das ideias e seus entrelaçamentos do que apenas nas coleções acabadas.

Restam entreaberto impasses relativos à adequação entre a natureza do problema investigado e as exigências do método. Neste caso, o objeto de pesquisa exige um olhar mais fluido, em que o próprio método nasce conectado a essas materialidades, demonstrando que a observação e análise também se constroem através desse modelo de rede-rizoma.

Um rizoma não começa nem conclui, ele se encontra sempre no meio, entre as coisas, inter-ser, intermezzo. (...) Entre as coisas não designa uma correlação localizável que vai de uma para outra e reciprocamente, mas uma direção perpendicular, um movimento transversal que as carrega uma e outra. (DELEUZE; GUATTARI, 1995, p. 37)

Portanto, o rizoma possui uma estrutura indefinida que vai se modificando de acordo com os novos agenciamentos ${ }^{3}$. Para melhor entender essa configuração os autores elaboram princípios que reforçam as características do rizoma. A saber, qualquer ponto de um rizoma pode ser conectado a qualquer outro e deve sê-lo, o que se tem são conexões por todos os lados e que mudam de acordo com esses novos agenciamentos. É muito diferente da árvore ou da raiz que fixam um ponto, uma ordem e são, antes de tudo, princípios de decalque, reprodutíveis ao infinito.

Ao contrário, um método rizoma é obrigado a analisar a linguagem efetuando um descentramento sobre dimensões e outros registros, ou seja, não existem num rizoma pontos fixos como se encontra numa estrutura concreta e linear. O rizoma é, no fundo, um mapa. Um mapa aberto que contribui para a conexão dos campos, e é conectável em todas as suas dimensões, desmontável, reversível, suscetível de receber modificações constantemente. Um dos princípios mais importantes do rizoma é a cartografia, uma questão de método que privilegia as múltiplas entradas e saídas.

Este pensamento afina-se com o de Preciosa (2010) que propõe:

Intuir a urgência de se fabular um procedimento de investigação da existência, que acolha nossos estranhamentos, nossos esgarçamentos identitários, nossos balbucios. Brotar pelo meio é opor-se a um destino que progride em direção a algo, é acariciar riscos, acumular êxitos e retumbantes fracassos, é se inflitrar por algumas vizinhanças, fazendo conexões, é povoar o cotidiano de incertezas, é recolher-se numa tenda de silêncios, num gesto de delicadeza diante do que está a se formar e maturar diante de si. (PRECIOSA, 2010, p. 37)

\footnotetext{
${ }^{3}$ Para entender o conceito de agenciamento, Deleuze e Guattari (1995b, p.29) traçam dois eixos acerca de sua natureza. Um comporta o conteúdo e a expressão; portanto, por um lado "ele é agenciamento maquínico de corpos, de ações e de paixões, misturas de corpos reagindo uns sobre os outros; por outro lado, agenciamento coletivo de enunciação, de atos e de enunciados, transformações incorpóreas sendo atribuídas aos corpos." No outro eixo, o agenciamento tem lados territoriais ou reterritorializados que o estabilizam, e outros desterritorializados que o arrebatam. Desse modo, em seu aspecto material, um agenciamento não é apenas produção de bens, mas um "estado preciso de mistura de corpos em uma sociedade". (DELEUZE; GUATTARRI, 1995b, p.31)
} 
Uma das entradas dessa pesquisa já localiza a criação em processo como um percurso não linear, em rede e, portanto, exige outro olhar do pesquisador ao lidar com afetos, sensibilidades, olhares, referências e angústias de um criador. Ao mesmo tempo, ao entrarmos em contato com o universo particular e compartilhado do designer, suas linhas condutoras são complexas e dinâmicas.

Como observar um caminho criativo tomado pela multiplicidade de entradas e saídas de extremos? Precisamos de novos mapas juntando fragmentos, raspas e restos, sem uma preocupação pela totalidade e sim pela multiplicidade. A prática da cartografia diz respeito a captar esses agenciamentos que o corpo faz inseparáveis de sua relação com o mundo.

Para isso, o cartógrafo absorve matérias de qualquer procedência. Tudo o que der língua para os movimentos do desejo, tudo o que servir para cunhar matéria de expressão e criar sentido. Para ele é bem vindo. Todas as entradas são boas desde que as saídas sejam múltiplas. Por isso, o cartógrafo serve-se de fontes as mais variadas, incluindo fontes não só escritas e nem só teóricas. (ROLNIK, 2006, p. 65)

Os agenciamentos que envolvem a relação do criador com seu tempo e seu espaço estabelecem o seu diálogo com a própria moda contemporânea. Através das pistas guardadas, encontramos a criação em processo e suas experimentações em forma de conteúdo e expressão; é, pois, uma construção das multiplicidades que formam tanto as suas coleções quanto o próprio criador e seu discurso através de uma imagem de moda construída.

Para entender esses deslocamentos, usamos a fala do teórico cultural Stuart Hall (2006) que discute que as identidades do sujeito na contemporaneidade são celebrações móveis, formadas e transformadas continuamente em relação às formas como somos interpelados nos sistemas culturais, ou seja, as identidades não são unificadas ao redor de um eu coerente; pelo contrário, são fragmentadas e estão sendo continuamente deslocadas.

Desses deslocamentos e entrelaçamentos surgem as roupas que cobrem nossos corpos. O estilista, no seu processo de criação, recolhe esses fragmentos por entre as redes culturais e a memória e suas extensões artificiais, lugares nos quais atualiza suas impressões e os transforma em narrativas vestíveis inacabadas: não no sentido das minúcias no acabamento dos detalhes, das costuras ou do avesso; são inacabadas no sentido de um processo contínuo que lida com esses pensamentos fragmentários interconectados no presente.

A atitude do pesquisador-cartógrafo é reconhecer que, se a pesquisa se propõe ao acompanhamento de processos em curso, as mudanças de rumo não são necessariamente indício de inconsistência do problema. E ainda, assumir a cartografia como direção metodológica exige que o cartógrafo "esteja mergulhado nas intensidades de seu tempo e que, atento às linguagens que encontra, devore as que Ihe parecerem elementos possíveis para a composição das cartografias que se fazem necessárias". (ROLNIK, 2006, p. 23)

O criador, além de difusor é um sujeito-receptor, que olha pelo prazer de olhar, vagando por ruas, textos, imagens, sons, links, cheiros, procurando algo que desperte seus sentidos e sua percepção. Ele busca uma perturbação, um desejo que gere o movimento criador. Além disso, um estilista faz muito mais do que construir roupas; ele 
constrói imagens de moda, que pretendem representar algo, gerar desejo no outro e que se encontram lá fora no espaço e tempo.

Rolnik (2006) discute que o desejo consiste no movimento de afetos e de simulações desses afetos em certas máscaras, movimento gerado no encontro dos corpos. Do mesmo modo, ainda segundo a autora, o desejo consiste também no movimento contínuo de desencantamento, ao surgirem novos afetos a partir de novos encontros. Portanto, essas intensidades são afetadas em certas matérias.

Da necessidade de dizer algo surgirão roupas, narrativas. Um impulso que gera uma ação entre processos emotivos e racionais. Uma escrita de Si que luta com tantos elementos para que eles dêem vozes aos seus desejos. Antes de qualquer coisa, o estilista é um observador, explorador, pesquisador.

Foucault (1992) discute a escrita de Si, como um movimento que visa captar o já dito; reunir aquilo que se pôde ouvir ou ler dessa experiência sensível de quem escreve com o seu tempo. Consideramos o registro do processo de criação, como uma escrita de Si, mesmo que esta no caso do criador de moda, raramente se dá pela palavra, mas mais intensamente pela imagem. Assim, nos apropriamos da idéia de Foucault para perceber, pelo jogo das imagens escolhidas e dos registros assimilados, a filiação dos pensamentos que ficaram gravados e que formam para si próprio, identidades.

Desse modo, o espaço dos registros, sejam eles de qualquer natureza, reserva o tempo da experimentação e amadurecimento das ideias, lugar do autor e da obra, pois ambos vão se constituindo simultaneamente. Foucault (1992) usa dois tipos de textos para discutir essa escrita de Si: o hypomnemata e a correspondência, memórias materiais das coisas lidas, ouvidas, acumuladas ou pensadas que possibilitam a releitura e a mediação.

Deslocando o lugar do texto verbal para uma tessitura visual, podemos entender algumas relações importantes dessa constituição de $\mathrm{Si}$, a partir do entendimento desses dois conceitos usados pelo autor.

Os hypomnemata não deveriam ser encarados como um simples auxiliar de memória, que poderiam consultar-se de vez em quando, se a ocasião se oferecesse. Não são destinados a substituir-se à recordação porventura desvanecida. Antes constituem um material e um enquadramento para exercícios a efetuar frequentemente: ler, reler, meditar, entretar-se a sós ou com outros. (FOUCAULT, 1992, p. 136)

Esse tipo de caderno de notas permite a constituição de Si a partir do recolhimento do discurso dos outros, fragmentos que o criador assimila de acordo com a sua sensibilidade e emoção. Não é uma narrativa de si mesmo, como os diários íntimos, como discute o autor, mas uma "apropriação, unificação e subjetivação de um 'já dito' fragmentário e escolhido” (FOUCAULT, 1992, p. 160)

Já a correspondência, texto por definição destinado a outrem, dá também lugar a um exercício pessoal, pois, ao escrever, estamos relendo o tempo todo e elaborando o que é dito. Além disso, o autor traz a tona uma discussão acerca da correspondência, que é bastante interessante como uma metáfora para entendermos uma escrita de $\mathrm{Si}$ compartilhada no Instagram.

A carta enviada atua, em virtude do próprio gesto da escrita, sobre aquele que a envia, assim como atua, pela leitura e a releitura, sobre aquele que a recebe. (...) A carta faz o escritor 
'presente' àquele a quem a dirige. E presente não apenas pelas informações que lhe dá acerca da sua vida, das suas atividades, dos seus sucessos e fracassos, das suas venturas ou infortúnios; presente de uma espécie de presença imediata e quase física. (FOUCAULT, 1992, p. 145-149)

Assim, ao ver uma imagem e decidir captar e compartilhar no aplicativo, esta imagem atua tanto no criador, pelo recorte e edição, quanto no receptor-seguidor do seu perfil, pelo ato da visualização da imagem. Assim, o estilista e seu universo particular mostram-se e se fazem presente junto ao outro. Porém, mesmo na prática dos diários íntimos aquele que escreve não revela todas as minúcias dos acontecimentos. A escrita de Si é uma seleção de fragmentos que formam uma autoimagem que queremos que o outro tenha de nós, uma autoficção.

Klinger (2008) parte da hipótese de que a autoficção inscreve-se no coração do paradoxo do final do século XX: entre um desejo narcisista de falar de si e o reconhecimento da impossibilidade de exprimir uma "verdade" na escrita. Não existe original e cópia, apenas construção simultânea no texto e na vida, na qual o sujeito que retorna nessa nova prática de escritura em primeira pessoa não é mais aquele que sustenta a autobiografia: a linearidade da trajetória da vida estoura em benefício de uma rede de possíveis narrativas ficcionais. Assim, a obra de autoficção também é comparável à arte da performance na medida em que ambos se apresentam como textos inacabados, improvisados, work in progress, como se o leitor assistisse "ao vivo" ao processo da criação.

Consideramos, então, os documentos de processos como um tipo de escrita de si e, portanto uma autoficção do estilista, lugar de construção de suas redes, de fluxos de pensamentos, de reformulação de suas práticas. Os acervos particulares são registros guardados em seu ateliê, fragmentos de outros discursos, que conservam o tempo da experimentação, da pausa e da contemplação. Já os acervos compartilhados são os registros imagéticos postados no Instagram do estilista, que guardam um tempo mais instantâneo, fragmentado, em que quase diariamente novas imagens vão compondo essa rede, que afeta quem compartilha e quem faz a leitura visual do compartilhamento.

Logo, as coleções carregam fragmentos desse work in progress e os documentos referentes ao seu processo criativo formam uma cartografia rizomática do criador, composta pelos seus registros, imagens, rascunhos, rejeições, linhas de fuga e suas conexões não lineares que constituem ilhas de referências em processo que aliam suas forças na invenção de novos arranjos.

No Instagram o mais significativo é perceber o exercício simulatório, combinatório, de provocar uma resposta da audiência contínua, escrevendo e lendo as imagens em deslocamento. Esta forma se dá através das escolhas de estilo, de memórias, do conhecimento interpessoal, do ordenamento e do mundo sendo mostrado em tempo real. As imagens continuam a se mover, a serem geradas. (SILVA JUNIOR, 2012)

Portanto, nesse aplicativo, a fotografia é o elemento que marca essa outra construção da memória de si; é outro tipo de acervo, nesse caso, pessoal e, simultaneamente, compartilhado, o que possibilita o exercício de guardar o que afeta 
o seu olhar e, ao mesmo tempo construir/editar uma imagem que o usuário quer que o outro tenha dele.

Nessa tensão entre o eu e o outro, o particular e o compartilhado, o estilista registra seu olhar, seus projetos, interage com o outro que de certa maneira pode interferir também em sua trajetória, já que com as tecnologias móveis e os territórios informacionais, a potência da emissão e da conexão aumenta ainda mais as práticas de colaboração e recombinação, aliando de forma mais forte comunicação, comunidade, sociabilidade e mobilidade. (LEMOS, 2009). O estilista constrói a Si como um criador em linhas fluidas, velozes, assim como a própria cibercultura.

Para Le Breton (2003), a cibercultura é outro principio da realidade que autoriza a identificação com milhares de formas possíveis, materializa a onipotência do pensamento. A vida cotidiana inteira pode se insinuar na web. Desse modo, quando o usuário do Instagram aperta o botão compartilhar, a imagem selecionada e postada não está desligada da dimensão do real, porém ela é sempre filtrada e, portanto, é uma mediação entre as coisas da sua vida, ele próprio e o outro.

O Instagram, nesse caso, permite aos seus usuários uma edição de si, e que não é neutra, pois, ao seguir e ser seguido por outros, ele constrói, simultaneamente e continuamente, uma imagem que gostaria que o outro tivesse dele. São fragmentos sampleados que articulados produzem sentidos.

Nesse conjunto de imagens percebemos que o todo traduz uma estética muito própria do estilista que compartilha seu universo particular. São pistas do seu filtro perceptivo cartografadas em conexão com as imagens impressas. Para Salles (2006), os elementos selecionados pelo criador já existem; a inovação está no modo como são colocados juntos, ou seja, na maneira como são transformados. As construções de novas realidades, pelas quais o processo criador é responsável, dão-se por meio de um percurso de transformações, o qual envolve seleções e combinações.

Difícil dizer qual imagem se relaciona com qual coleção, ou com qual detalhe de algum dos seus vestidos. O importante é que a recorrência das imagens de assuntos semelhantes nos dá pistas para refletir para onde olha este criador.

Ao observar o mundo ao seu redor, o estilista é muitas vezes tomado por coisas que afetam a sua sensibilidade e, para que esses encontros não sejam esquecidos, ele os registra de alguma maneira. Seja em um esboço num pedaço de papel, em uma fotografia ou em uma postagem nas redes sociais. De uma forma ou de outra, a escrita de Si guarda o percurso rizomático de criação e seus "já ditos" como também as marcas pessoais do criador e de suas coleções em construção.

\section{PONTO EM SEGUIDA}

Desenvolver uma coleção de moda é antes de tudo uma manifestação do desejo de se expressar através de roupas, que se inicia ao olhar mundos, repertoriar referências e descobrir novos territórios. Em seu processo de criação, alguns designers de moda estabelecem diálogos entre o ateliê e o Instagram, entre imagens particulares e compartilhadas.

No processo de criação na contemporaneidade, a construção do seu pensamento no ato de criar parte de um percurso visual pautado por uma edição que 
é rizomática. Essa edição não busca linearidade, mas sim explicita a simultaneidade de vários fragmentos, que através do seu olhar de editor-criador se desdobram na criação de roupas. Em busca de redes de conexões entre as imagens, o modo como Deleuze e Guattari apresentam os conceitos de rizoma e cartografia referencia o mapa aberto das referências imagéticas editadas pelo designer e permitem compreender melhor os sentidos que se formas a partir dessas conexões.

Assim, compreendemos que o designer articula suas impressões, seus registros e seus pensamentos produzindo coleções que traduzem parte do seu universo particular. Portanto, o interesse não é relatar ou reproduzir o processo de criação do estilista, e sim realizar atravessamentos tanto entre os registros do criador, seu mundo e os conceitos. Uma cartografia dessas construções de Si.

\section{REFERÊNCIAS}

BARBERO, Jesús Martín. Ofício do cartógrafo: Travessias latino-americanas da comunicação na cultura. São Paulo: Edições Loyola, 2004

DELEUZE, Gilles. Parte $Z$, Abecedário Deleuze. Disponível em: http://www.youtube.com/watch?v=FPp8uC2WqYc. Acesso em 16 de set. de 2012

O ato de criação. Palestra realizada em 1987. Trad. José Marcos Macedo. Folha de São Paulo, Caderno Mais! São Paulo, 27 de junho de 1999.

DELEUZE, Gilles; GUATTARI, Félix. Mil Platôs - capitalismo e esquizofrenia. Vol.1. Rio de Janeiro: Ed. 34, 1995.

Mil Platôs - capitalismo e esquizofrenia. Vol.2. Rio de Janeiro: Ed. 34, 1995b.

Mil Platôs - capitalismo e esquizofrenia. Vol.5. Rio de Janeiro: Ed. 34, 1997.

FOUCAULT, Michel. A escrita de si. In: O que é um autor? Lisboa: Passagens. 1992. pp.129-160

HALL, Stuart. A identidade cultural da Pós-modernidade. Rio de janeiro: DP\&A Editora, 2006

KLINGER, Diana. Escrita de si como performance. In: Revista Brasileira de Literatura Comparada. N. 12. São Paulo: 2008. Disponível em: http://www.abralic.org.br/revista/2008/12

LE BRETON, David. Adeus ao corpo. Antropologia e sociedade. Campinas-SP: Papirus, 2003.

LEMOS, André. Cibercultura: tecnologia e vida social na cultura contemporânea. Porto Alegre: Sulina, 2002.

MANOVICH, Lev. Novas mídias como tecnologia e idéia: dez definições. In: O chip e o calendoscópio: reflexões sobre as mídias sociais./ Lucia Leão, organizadora. São Paulo: Editora SENAC, 2005.

PRECIOSA, Rosane. Pensar a Moda Brasileira como um lugar de contaminações: algumas reflexões preliminares. In: 5o Colóquio de Moda, 2009, Recife. 
Rumores discretos da subjetividade: sujeito e escritura em processo. Porto Alegre: Sulina: Editora da UFRGS, 2010.

ROLNIK, Suely. Cartografia sentimental: transformações contemporâneas do desejo. Porto Alegre: Sulina; Editora da UFRGS, 2006.

SALLES, Cecília Almeida. Gesto Inacabado. São Paulo: FAPESP: Annablume, 2004

Horizonte, 2006

Redes de criação: construção da obra de arte. São Paulo: Editora

SILVA JUNIOR; José Afonso. Da fotografia expandida à Fotografia desprendida: como o Instagram explica a crise da Kodak e vice-versa. In: Intercom - Sociedade Brasileira de Estudos Interdisciplinares da Comunicação XXXV Congresso Brasileiro de Ciências da Comunicação, 2012, Fortaleza. 